\title{
Acanthamoeba-mediated cytopathic effect correlates with MBP and AhLBP mRNA expression
}

\author{
Sook-Luan Ng${ }^{1}$, Anisah Nordin², Norzana Abd Ghafar ${ }^{3}$, Yusof Suboh², Noraina Ab Rahim² and Kien-Hui Chua ${ }^{\text {* }}$
}

\begin{abstract}
Background: In recent years, the concern of Acanthamoeba keratitis has increased since the infection is often associated with contact lens use. Partial $18 \mathrm{~S}$ rRNA genotypic identification of Acanthamoeba isolates is important to correlate with pathophysiological properties in order to evaluate the degree of virulence. This is the first report of genotypic identification for clinical isolates of Acanthamoeba from corneal scrapings of keratitis in Malaysia. This study is also the first to correlate the mRNA expression of MBP and AhLBP as virulent markers for axenic strains of Acanthamoeba.

Results: In this study, ten clinical isolates were obtained from corneal scrapings. Rns genotype and intra-genotypic variation at the DF3 region of the isolates were identified. Results revealed that all clinical isolates belonged to the T4 genotype, with T4/6 (4 isolates), T4/2 (3 isolates), T4/16 (2 isolates) and one new genotype T4 sequence (T4/36), being determined. The axenic clinical isolates were cytopathogenic to rabbit corneal fibroblasts. MBP and AhLBP mRNA expression are directly correlated to Acanthamoeba cytopathic effect.

Conclusions: All ten Malaysian clinical isolates were identified as genotype T4 which is predominantly associated with AK. Measuring the mRNA expression of Acanthamoeba virulent markers could be useful in the understanding of the pathogenesis of Acanthamoeba keratitis.
\end{abstract}

Keywords: Keratitis, Acanthamoeba, Genotype, Cytopathic, MBP, AhLBP

\section{Background}

Photophobia, severe pain, redness and tearing are the common symptoms of Acanthamoeba keratitis (AK). AK is a rare but sight-threatening corneal infection which is caused by the free-living amoebae of the genus Acanthamoeba [1]. These organisms are widely distributed in the air, soil, water and domestic water tap, etc. [2,3]. AK is characterized by severe pain due to radial neuritis, and a ring-like stromal infiltrate appears in the advanced stage of AK [4]. Poor vision or even visual loss occurs due to corneal scarring if proper treatment is delayed. In recent years, the concern of AK has increased since this infection is often associated with contact lens contamination, especially in urban areas. The increasing use of contact lenses for visual and cosmetic purposes, combined with improper cleaning and storage practices could be the reason for the increase in the number of AK

\footnotetext{
*Correspondence: ckienhui@gmail.com

${ }^{1}$ Department of Physiology, Faculty of Medicine, Universiti Kebangsaan

Malaysia, Jalan Yaacob Latif, 56000 Kuala Lumpur, Bandar Tun Razak, Malaysia

Full list of author information is available at the end of the article
}

infections $[5,6]$. The first reported AK case in Malaysia was also related with a contaminated contact lens [7].

Morphological classification of Acanthamoeba, as described by Pussard \& Pons [8] is less reliable due to the possible alteration of cyst shape by the ionic strength of the growth medium [9]. Genotyping is a useful tool in the taxonomic and epidemiological study of AK and provides a correlation between genotype and phenotypes of Acanthamoeba isolates [10]. Recently, the most promising method to identify the Acanthamoeba genotype is the sequencing of the complete nuclear $18 \mathrm{~S}$ rRNA (Rns) gene [11]. Following this, the previous studies found that the partial 18S rRNA gene sequences which contain the Acanthamoeba genus-specific amplicon (ASA.S1) were sufficient to identify the Acanthamoeba Rns genotypes. ASA.S1 includes a region called diagnostic fragment 3 (DF3) which encodes a highly variable stem 29-1used for genotype discrimination $[11,12]$. There were 20 genotypes identified and designated as T1-T4 [13], T5-T12 [14], T13 [15], T14 [16], T15 [17], T16 [18], T17 [19], 
T18 [20] and T19-T20 [21]. The T4 genotype is the predominant sequence type associated with AK [14]. Other Rns genotypes have also been reported as a causative agent for AK, such as T2 [22], T3 [14], T5 [10], T6 [23], T10 [19], T11 [13] and T15 [24].

Physiological properties and genotyping of Acanthamoeba should be studied simultaneously to evaluate the pathogenic potential of the isolates. Cytopathic tests could be used as a pathogenic marker to determine the degree of virulence of the interested Acanthaoeba isolates; virulent isolates are able to induce a cytopathic effect but nonpathogenic Acanthamoeba cannot [25]. The cytoadherence of Acanthamoeba to mannosylated glycoproteins on the corneal epithelial cells is a critical step to initiate the Acanthamoeba keratitis [26, 27]. It has been shown that the adhesion of Acanthamoeba to host cells is mediated by the mannose binding protein (MBP) on the surface of trophozoites. Through MBP-mediated adhesion to host cells, the amoebae produce a contact-dependent mechanism which able to exhibit a cytopathic effect involving direct cytolysis, phagocytosis, apoptosis and proteolytic activity [28].

Acanthamoeba trophozoites are stimulated to produce $133 \mathrm{kDa}$ mannose induced protein after exposure to the upregulated mannose-specific lectins in the ulcerated corneal epithelium and lead to the activation and upregulation of matrix metalloproteinases in corneal cells $[29,30]$. Besides that, the ability of Acanthamoeba to adhere on the laminin of the Bowman's membrane and extracellular matrix via its Acanthamoeba laminin binding protein (AhLBP), is also important to allow Acanthamoeba to invade the corneal stroma in AK [31]. Acanthamoeba were capable of adhering and invading the extracellular matrix components such as laminin and collagen type I [32]. Previous studies provided information on the role of MBP and AhLBP as the marker of pathogenicity, mostly in protein level and a few in DNA works [31,33-36].

Genotyping of Acanthamoeba isolates is still underreported in Malaysia. This study, therefore, aimed to determine the Rns genotype of Malaysian clinical isolates from corneal scrapings by analyzing the intra-genotypic variation at the DF3 region. The characterization of morphological and cytopathic properties for Acanthamoeba isolates was studied. This study is the first evaluation of mRNA expression of MBP and AhLBP quantitatively for Acanthamoeba spp. and correlates both virulent markers and their growth rate with cytopathic effect.

\section{Methods}

\section{Sample collection}

Ten Acanthamoeba isolates are maintained cultures which were obtained from the Acanthamoeba Culture Laboratory of Parasitology Department, UKM. The source of the samples is described in Table 1. The isolates were cultured on a non-nutrient agar (NNA) plate and overlaid with
$150 \mu \mathrm{l}$ of heat-killed Escherichia coli at $30^{\circ} \mathrm{C}$. A small piece of agar containing cysts was removed from the primary culture and transferred to another new NNA plate, which was continued until it was totally free from co-contaminant, and the culture is known as a xenic culture. Two week-old cysts were harvested from the NNA plate and washed with PAGE amoebic saline (PAS) solution twice and then incubated overnight with $0.5 \mathrm{~N}$ sterile $\mathrm{HCl}$ during the process of axenization. The cysts were washed with PAS solution three times and centrifuged at $500 \times g$ for $10 \mathrm{~min}$ to obtain the cyst pellet. The cyst pellet was suspended with enriched PYG medium ( $4 \%$ peptone, $4 \%$ yeast extract, $2 \%$ glucose) supplemented with 10\% fetal bovine serum (FBS; Gibco, Grand Island, New York, USA), 1\% antibiotic-antimycotic (Gibco) and cultured in a T-25 flask (Greiner Bio-One, Frickenhausen, Germany) at $37{ }^{\circ} \mathrm{C}$. The PYG medium was adjusted to $\mathrm{pH}$ 7.2. The axenic trophozoites were excysted in the PYG medium after 1 day of incubation. The axenic cultures were subcultured every 3 days.

\section{Identification of Acanthamoeba}

A wet smear of xenic cultures was observed under a light microscope for the morphology features of trophozoites and cysts. The diameter of cysts was measured using the VideoTest Morphology software (VideoTest, Saint Petersburg, Russia, version 5). Isolates were classified as Acanthamoeba spp. groups I, II or III according to the keys of Pussard \& Pons [8].

The 18S rDNA identification of Acanthamoeba spp. was performed as per the following procedures. Acanthamoeba isolates with a density of $5 \times 10^{5}$ trophozoites were harvested from NNA plates and DNA was extracted with a commercially available AccuPrep ${ }^{\circ}$ Genomic DNA Extraction Kit (Bioneer, Daejeon, Korea). The pelleted trophozoites were resuspended in $200 \mu \mathrm{l}$ PAS solution, mixed with $20 \mu \mathrm{l}$ proteinase $\mathrm{K}$ and $200 \mu \mathrm{l}$ binding buffer and incubated at $60{ }^{\circ} \mathrm{C}$ for $10 \mathrm{~min}$. The lysate was transferred into the upper reservoir of the binding column tube after added $100 \mu \mathrm{l}$ isopropanol. The tube was centrifuged at $8000 \times g$ for $1 \mathrm{~min}$. The binding column tube was washed with $500 \mu \mathrm{l}$ ethanol twice and the DNA was eluted with $200 \mu \mathrm{l}$ elution buffer. After that, amplicon ASA.S1 was amplified by PCR using Platinum ${ }^{\circ}$ Taq DNA Polymerase High Fidelity kit (Invitrogen, Carlsbad, CA, USA) following the recommended protocol with genusspecific primers JDP1 and JDP2 (Table 2). The PCR reaction was started with incubation at $94{ }^{\circ} \mathrm{C}$ for $3 \mathrm{~min}$, followed with 35 cycles of $30 \mathrm{~s}$ at $94{ }^{\circ} \mathrm{C}, 30 \mathrm{~s}$ at $61^{\circ} \mathrm{C}$ and $1 \mathrm{~min}$ at $72{ }^{\circ} \mathrm{C}$. Incubation for another $5 \mathrm{~min}$ at $72{ }^{\circ} \mathrm{C}$ was done for final extension. Amplification products were visualized by ethidium bromide staining in $1.5 \%$ agarose gel electrophoresis and followed by gel extraction using PureLink $^{\text {tw }}$ quick gel extraction kit (Invitrogen). ASA.S1 PCR products were ligated into a plasmid vector by using 
Table 1 Acanthamoeba spp. isolates used in the present study for clinical isolates and reference strains

\begin{tabular}{|c|c|c|c|}
\hline Acanthamoeba spp. isolates & Source & Genotype Rns/ DF3 sequence & GenBank ID \\
\hline \multicolumn{4}{|l|}{ Clinical isolates } \\
\hline AC20 & Left corneal scraping & $\mathrm{T} 4 / 6$ & KY964312 \\
\hline UKMAC1 & Right corneal scraping & $\mathrm{T} 4 / 6$ & KY964313 \\
\hline UKMAC2 & Right corneal scraping & $\mathrm{T} 4 / 6$ & KY964314 \\
\hline UKMAC3 & Right corneal scraping & $\mathrm{T} 4 / 6$ & KY964315 \\
\hline UKMAC4 & Right corneal scraping & $\mathrm{T} 4 / 22$ & KY964316 \\
\hline UKMAC5 & Right corneal scraping & $\mathrm{T} 4 / 2$ & KY964317 \\
\hline UKMAC6 & Left corneal scraping & $\mathrm{T} 4 / 16$ & KY964318 \\
\hline UKMAC7 & - & $\mathrm{T} 4 / 2$ & KY964319 \\
\hline UKMAC8 & Corneal scraping & $\mathrm{T} 4 / 2$ & KY964320 \\
\hline UKMAC9 & Left corneal scraping & $\mathrm{T} 4 / 16$ & KY964321 \\
\hline \multicolumn{4}{|l|}{ Reference strains } \\
\hline P1CS & Corneal scraping & $\mathrm{T} 4 / 1$ & AF441812 \\
\hline P91CS & Corneal scraping & $\mathrm{T} 4 / 2$ & AF441808 \\
\hline P97LCSS1 & Contact lens case solution & $\mathrm{T} 4 / 3$ & AF441794 \\
\hline P97RCLS2 & Right contact lens & $\mathrm{T} 4 / 4$ & AF441796 \\
\hline P97LCLS2 & Left contact lens & $\mathrm{T} 4 / 5$ & AF441795 \\
\hline P120CS & Corneal scraping & $\mathrm{T} 4 / 6$ & AF441810 \\
\hline P209CS & Corneal scraping & $\mathrm{T} 4 / 7$ & AF441802 \\
\hline C10TA & Tape & $\mathrm{T} 4 / 8$ & AF441799 \\
\hline C68TA & Tape & $\mathrm{T} 4 / 9$ & AF441803 \\
\hline C124LC & Contact lens case & $\mathrm{T} 4 / 10$ & AF441798 \\
\hline BP:P20:LCS & Left corneal scraping & $\mathrm{T} 4 / 11$ & FJ422511 \\
\hline BP:P8:LCS & Left corneal scraping & $\mathrm{T} 4 / 12$ & FJ422512 \\
\hline BP:P1:RCS & Right corneal scraping & $\mathrm{T} 4 / 13$ & FJ422513 \\
\hline BP:P6:LCS & Left corneal scraping & $\mathrm{T} 4 / 14$ & FJ422524 \\
\hline BP:P7:RCL & Right corneal scraping & $\mathrm{T} 4 / 15$ & FJ422526 \\
\hline BP:P15:RCS & Right corneal scraping & $\mathrm{T} 4 / 16$ & FJ422527 \\
\hline BP:P9:LCS & Left corneal scraping & $\mathrm{T} 4 / 17$ & FJ422537 \\
\hline BP:P14:LCS & Left corneal scraping & $\mathrm{T} 4 / 18$ & FJ422533 \\
\hline BP:P22:LCS & Left corneal scraping & $\mathrm{T} 4 / 19$ & FJ422535 \\
\hline BP:P13:CB & Cornea & $\mathrm{T} 4 / 20$ & FJ422536 \\
\hline BP:P16:RCS & Right corneal scraping & $\mathrm{T} 4 / 21$ & FJ422541 \\
\hline AKSI001 & Corneal scraping & $\mathrm{T} 4 / 22$ & GQ342612 \\
\hline AKSI002 & Corneal button & $\mathrm{T} 4 / 23$ & GQ342613 \\
\hline AKSIO03 & Corneal button & $\mathrm{T} 4 / 24$ & GQ342614 \\
\hline AKSIO04 & Corneal button & $\mathrm{T} 4 / 25$ & GQ342615 \\
\hline AKSI008 & Corneal button & $\mathrm{T} 4 / 26$ & GQ342619 \\
\hline AKSI011 & Corneal button & $\mathrm{T} 4 / 27$ & GQ342622 \\
\hline AKSI014 & Corneal button & $\mathrm{T} 4 / 28$ & GQ342625 \\
\hline AC6 (T4/22) & Corneal scraping & $\mathrm{T} 4 / 29$ & AB554223 \\
\hline AC15 (T4/23) & Corneal scraping & $\mathrm{T} 4 / 30$ & AB554225 \\
\hline CDC V328 & GAE, brain & $\mathrm{T} 4 / 31$ & AY702999 \\
\hline ACL-JN15 & Corneal scraping & $\mathrm{T} 4 / 32$ & HF930505 \\
\hline
\end{tabular}


Table 1 Acanthamoeba spp. isolates used in the present study for clinical isolates and reference strains (Continued)

\begin{tabular}{|c|c|c|c|}
\hline Acanthamoeba spp. isolates & Source & Genotype Rns/ DF3 sequence & GenBank ID \\
\hline AcL-LA16 & Keratitis & $\mathrm{T} 4 / 33$ & HF930509 \\
\hline ACL-GF8 & Corneal scraping & $\mathrm{T} 4 / 34$ & HF930500 \\
\hline WAL (T4/29) & Keratitis & $\mathrm{T} 4 / 35$ & JX441875 \\
\hline A. castellanii CDC:0981:V006 & GAE, brain, Georgia, USA & $\mathrm{T} 1$ & U07400 \\
\hline A. palestinensis Reich ATCC30870 & Soil, Israel & $\mathrm{T} 2$ & U07411 \\
\hline A. griffini $(\mathrm{H} 37)$ & Keratitis, Scotland, UK & $\mathrm{T} 3$ & S81337 \\
\hline A. griffini S-7 ATCC 30731 & Beach bottom, Connecticut, USA & T3 & U07412 \\
\hline A. culbertsoni Diamond & Keratitis, Ohio, USA & T4 & AF019057 \\
\hline A. castellanii CDC:0814:V014 & Keratitis, India & T4 & U07401 \\
\hline A. castellanii Castellani ATCC50374 & Yeast culture, UK & T4 & U07413 \\
\hline A. polyphaga ATCC30461 & $\begin{array}{l}\text { Human corneal scraping, Houston, } \\
\text { Texas, USA }\end{array}$ & T4 & AY026243 \\
\hline Acanthamoeba sp. ATCC 50369 & Keratitis, Texas, USA & T4 & U07409 \\
\hline A. hatchetti strain $2 \mathrm{HH}$ & Keratitis, Austria & $\mathrm{T} 4$ & AF260722 \\
\hline A. lenticulata Jc-1 ATCC50428 & Fresh water stream, New York, USA & T5 & U94739 \\
\hline A. lenticulata strain 45 ATCC50703 & Human nasal mucosa, Germany & T5 & U94730 \\
\hline A.lenticulata PD2S ATCC30841 & Swimming pool, France & T5 & U94741 \\
\hline A. palestinensis 2802 ATCC50708 & Swimming pool, France & T6 & AF019063 \\
\hline A. astronyxis Ray Hayes ATCC30137 & Laboratory water, Washington, USA & $\mathrm{T7}$ & AF019064 \\
\hline A. tubiashi OC-15C ATCC30867 & Fresh water, Maryland, USA & T8 & AF019065 \\
\hline A. comandoni ATCC30135 & Soil, France & T9 & AF019066 \\
\hline A. culbertsoni Lily A-1 ATCC30171 & Human cell culture, Indiana, USA & $\mathrm{T} 10$ & AF019067 \\
\hline A. hatchetti $\mathrm{BH}-2$ & Brackish water, Maryland, USA & T11 & AF019068 \\
\hline A. healyi CDC 1283:V013 & GAE, brain, Barbados, BWI & $\mathrm{T} 12$ & AF019070 \\
\hline Acanthamoeba sp. UWET39 & Soil, Washington, USA & $\mathrm{T} 13$ & AF132136 \\
\hline Acanthamoeba sp. UWC9 & Contact lens case & $\mathrm{T} 13$ & AF132134 \\
\hline Acanthamoeba sp. PN15 & Clinical sample, Pakistan & T14 & AF333607 \\
\hline A. jacobsi AC005 ATCC30732 & Sea sediment, New York Bight Apex & T15 & AY262360 \\
\hline A. jacobsi AC305 & Untreated water system, Australia & T15 & AY262365 \\
\hline Acanthamoeba sp. cvX & Freshwater pond, Italy & T16 & GQ380408 \\
\hline Acanthamoeba sp. U/H-C1 & Freshwater pond, Italy & T16 & AY026245 \\
\hline Acanthamoeba sp. Ac E1a & Lampangpuri pond, Bangkok, Thailand & $\mathrm{T} 17$ & GU808277 \\
\hline Acanthamoeba sp. Ac E9b & $\begin{array}{l}\text { Freshwater pond, National Stadium, } \\
\text { Bangkok, Thailand }\end{array}$ & $\mathrm{T} 17$ & GU808302 \\
\hline Acanthamoeba sp. CDC: V621 clone 10 & GAE & T18 & KC822470 \\
\hline Acanthamoeba sp. USP AWW A68 & Water treatment plant, Spain & T19 & KJ413084 \\
\hline Acanthamoeba sp. AM-3H/T16 & River water, Poland & T20 & HQ632777 \\
\hline Acanthamoeba sp. M22/T16 & Bronchoaspirate fluid, Poland & T20 & GQ342607 \\
\hline Acanthamoeba sp. OSU 04-023 clone 2 & Liver tissue, Toucan & $\mathrm{T} 20$ & DQ451162 \\
\hline Acanthamoeba sp. OSU 04-020 clone 2 & Liver tissue, Toucan & T20 & DQ451161 \\
\hline
\end{tabular}

a T/A cloning kit (Invitrogen). Plasmids of identified positive clones were extracted using PureLink ${ }^{\mathrm{TM}}$ Quick Plasmid Miniprep kit (Invitrogen) and sequenced with ABI prism ${ }^{\text {тм }}$ Bigdye $^{\mathrm{TM}}$ terminator cycle using primer M13 (Applied Biosystems, Foster City, CA, USA).
The alignment of interesting sequences with homologous sequences from GenBank was conducted using BLAST (http://www.ncbi.nlm.nih.gov). Phylogenetic analyses were conducted in MEGA7 (Molecular Evolutionary Genetic Analysis software, version 7) [37]. The evolutionary history was 
Table 2 Primers used for PCR and RT-PCR reactions in this study

\begin{tabular}{|c|c|c|c|c|c|}
\hline Accession no. & Gene & Direction & Sequence & Amplicon size (bp) & Source \\
\hline \multicolumn{6}{|c|}{ Genotyping primers } \\
\hline \multirow[t]{2}{*}{ JDP } & ASA.1 & Forward & 5'-GGCCCAGATCGTTTACCGTGAA-3' & $423-551$ & [11] \\
\hline & & Reverse & 5'-TCTCACAAGCTGCTAGGGAGTCA-3' & & \\
\hline \multicolumn{6}{|c|}{ Acanthamoeba virulent marker primers } \\
\hline \multirow[t]{2}{*}{ U29609 } & ARP2 & Forward & 5'-GCTGTCTTGACCCTCTACGC-3' & 101 & Present study \\
\hline & & Reverse & 5'-AGCGAGAAGCCCTCGTACAC-3' & & \\
\hline \multirow[t]{2}{*}{ AY604040 } & MBP & Forward & 5'-AGGGCGAGACCTACGATAGC-3' & 165 & Present study \\
\hline & & Reverse & 5'-CCTCGTAGACGAAGGTGAGG-3' & & \\
\hline \multirow[t]{2}{*}{ AY351649 } & AhLBP & Forward & 5'-CCAACACCGACTCTCCTCTC-3' & 183 & Present study \\
\hline & & Reverse & 5'-CTCCTCAGGGTCACGGTAGA-3' & & \\
\hline
\end{tabular}

inferred using the Neighbor-Joining method [38]. The bootstrap consensus tree inferred from 1000 replicates [39] was taken to represent the evolutionary history of the taxa analyzed [39]. Branches corresponding to partitions reproduced in fewer than $50 \%$ bootstrap replicates were collapsed. The percentage of replicate trees in which the associated taxa clustered together in the bootstrap test (1000 replicates) was shown next to the branches [39]. The tree was drawn to scale, with branch lengths in the same units as those of the evolutionary distances used to infer the phylogenetic tree. The evolutionary distances were computed using the Kimura 2-parameter method [40] and were in the units of the number of base substitutions per site. All positions containing alignment gaps and missing data were eliminated only in pairwise sequence comparisons. The alignment of DF3 sequences was performed using MEGA 7 with ClustalW. The reference sequences used in this study are available in GenBank under the accession numbers shown in Table 1.

\section{Cytopathic effect}

Rabbit corneal fibroblasts were isolated from the cornea of New Zealand white strain rabbits as described in the previous study [41]. The rabbit heads were bought from the slaughter farm in Ijok, Malaysia. The corneal stroma was digested using collagenase type I solution in order to isolate the corneal fibroblasts. The corneal fibroblasts were then cultured on a $24 \times 24 \mathrm{~mm}$ coverslip in $35 \mathrm{~mm}$ tissue culture dishes (Orange Scientific, Braine-L'Alleud, Belgium) with F12:DMEM supplemented with 10\% FBS, 1\% Glutamax, 1\% antibiotic-antimycotic (Invitrogen) at $37{ }^{\circ} \mathrm{C}$ with atmospheric $\mathrm{O}^{2}$ and $5 \% \mathrm{CO}^{2}$ level. The cell culture medium contained sodium bicarbonate and HEPES solution which was used as buffer to maintain the media at $\mathrm{pH}$ 7.2-7.6. The $100 \%$ confluent cells were treated with 3 densities of axenic trophozoites, which were $10^{4}, 10^{5}$ and $10^{6}$ trophozoites per dish/well for triplicates at 3 time intervals (3, 6 and $24 \mathrm{~h}$ ). The cells were fixed using $4 \%$ paraformaldehye and stained with giemsa. The area of remaining cells after cytolysis was observed under a light microscope and measured using the
VideoTest Morphology software. The percentage of cytopathic effect (CPE) was calculated based on the surface area of empty spaces in the culture.

\section{Growth rate of trophozoites}

The growth rate of axenic trophozoites was performed in triplicates based on the trypan blue exclusion method using a haemocytometer (Weber Scientific International Ltd., Teddington, UK). Each axenic isolate was seeded with $1 \times$ $10^{5}$ trophozoites per well into 6-well plate (Nunc ${ }^{\mathrm{Tm}}$, Wiesbaden, Denmark) and cultured with PYG medium at $37{ }^{\circ} \mathrm{C}$ for $24 \mathrm{~h}$. The harvested trophozoites were stained with trypan blue vital dye (Gibco) and then directly counted. The formula for the growth rate was: difference between the final live trophozoite count and initial seeding, divided by the surface area $\left(9.6 \mathrm{~cm}^{2}\right)$ and days of confluence (1 day). Each sample with 1 million axenic trophozoites was lysed using $1 \mathrm{ml}$ TRI reagent in order to preserve the total RNA.

\section{mRNA expression of Acanthamoeba mannose binding} protein and laminin binding protein

Total RNA extraction of axenic Acanthamoeba was performed using TRI Reagent (Molecular Research Center, Cincinnati, USA) according to the manufacturer's protocol. The lysate was then separated into the aqueous and organic phases with the addition of $200 \mu \mathrm{l}$ chloroform and centrifugation at $12,000 \times \mathrm{rpm}$ for $15 \mathrm{~min}$. RNA remained exclusively in the aqueous phase and precipitated by $500 \mu \mathrm{l}$ isopropanol and $5 \mu \mathrm{l}$ polyacryl carrier (Molecular Research Center). The precipitated RNA was washed with $1 \mathrm{ml} 75 \%$ ethanol and solubilized with $20 \mu \mathrm{l}$ RNAse and DNAse free distilled water (Invitrogen). The quantity and purification of total RNA were determined by a Nanodrop ND-100 spectrophotometer (Nanodrop Technologies, Wilmington, Delaware, USA). SuperScript $^{\text {Ta }}$ III First-Strand Synthesis SuperMix (Invitrogen) was used to synthesise complementary DNA (cDNA) from $100 \mathrm{ng}$ of total RNA according to the manufacturer's protocol. The master mix of cDNA 
synthesis included $10 \mu \mathrm{l}$ of $2 \times$ reaction mix, $5 \mu \mathrm{l}$ total RNA, $3 \mu$ diethylpyrocarbonate-treated water and $2 \mu \mathrm{l}$ reverse transcriptase enzyme. The reverse transcription was initiated with $10 \mathrm{~min}$ at $23{ }^{\circ} \mathrm{C}$ for primer annealing, $60 \mathrm{~min}$ at $50{ }^{\circ} \mathrm{C}$ for reverse transcription and $5 \mathrm{~min}$ at $85{ }^{\circ} \mathrm{C}$ for reaction termination. The primers (forward and reverse) were designed from NIH GenBank using Primer Output 3 software (Table 2). Acanthamoeba actin related protein 2 (ARP2) is used as housekeeping gene in this study [42, 43]. Quantitative polymerase chain reactions were performed using MyiQ cycler (Bio-Rad, Hercules, CA, USA) with $\mathrm{iQ}^{\mathrm{m}} \mathrm{SYBR}^{\circ}$ Green Supermix (Bio-Rad, Hercules, CA, USA). The master mix of qRTPCR consisted of $12.5 \mu$ l of $2 \times$ SYBR Green Supermix, $1 \mu \mathrm{l}$ cDNA, $9.5 \mu \mathrm{l}$ RNase and DNase free distilled water, $1 \mu \mathrm{l}$ of $5 \mu \mathrm{M}$ forward primer and $1 \mu \mathrm{l}$ of $5 \mu \mathrm{M}$ reverse primer. The reaction profile involved pre-denaturation for 3 min at $95{ }^{\circ} \mathrm{C}$, PCR amplification for 40 cycles of $30 \mathrm{~s}$ at $95^{\circ} \mathrm{C}$ and $30 \mathrm{~s}$ at $61{ }^{\circ} \mathrm{C}$, with a final extension for $1 \mathrm{~min}$ at $72{ }^{\circ} \mathrm{C}$ and melting curve analysis. The specificity of PCR products was confirmed with melting curve analysis and $1.5 \%$ agarose gel electrophoresis. Relative mRNA expression of the virulent genes was calculated based on their qRT-PCR threshold cycle $(\mathrm{Ct})$ value using the formula of $2^{\wedge}$ (housekeeping gene $\mathrm{Ct}$ value - virulent gene $\mathrm{Ct}$ value).

\section{Statistical tests}

Quantitative data were tested for statistical significance using the Statistical Package for Social Sciences version 20 (IBM Corporation, Armonk, New York, USA). Student's t-test for independent samples was performed for normally distributed data, while the Mann-Whitney U-test was used as a non-parametric test. Correlation between two variables was analysed using Pearson's correlation coefficient. The results were presented as the mean \pm standard error mean (SEM). $P<0.05$ was considered to be statistically significant.

\section{Results}

\section{Identification of Acanthamoeba}

In this study, all the Malaysian clinical isolates from corneal scrapings were identified as Rns genotype T4. Currently, there were $35 \mathrm{~T} 4$ subgenotypes with deposited GenBank data and published in the articles, which were T4/1 to T4/ 10 [12], T4/11 to T4/21 [10] and T4/22 to T4/28 [44]. Another study also independently reported the same designation of T4/22 and T4/23 on the same year [45]. Therefore, Risler et al. [46] renamed the designation of $\mathrm{T} 4 / 22$ and $\mathrm{T} 4 /$ 23 identified by the study of Abe \& Kimata [45] to T4/29 and $\mathrm{T} 4 / 30$. Besides that, the T4 subgenotypes from T4/31 to T4/34 were also reported by them [46]. On the same year, another study also reported the same designation to T4/29 independently [47]. Thus, this study named the T4/29 identified by Duarte et al. [47] to T4/35. We found that isolate UKMAC4 possessed a new T4 sequence in the GenBank database. This isolate was $98 \%$ similar to A. hatchetti strain $2 \mathrm{HH}$ from a keratitis patient in Austria. Hence, isolate UKMAC4 was designated as T4/36 in this study. On the other hand, 8 out of 10 isolates have been determined phylogenetically as identical to other previously identified genotype T4 Rns isolates. The sequences of UKMAC1, UKMAC2, UKMAC3 and AC20 were similar to A. culbertsoni Diamond and belonged to T4/6 based on the DF3 sequence determination. Rns sequencing also demonstrated that three isolates, UKMAC5, UKMAC7 and UKMAC8 were identical to each other and similar to two ocular samples from France, which were Acanthamoeba spp. S22 and S36 (DQ87314 and EU146073, respectively). These isolates were determined as T4/2 and also $99 \%$ similar to A. castellanii CDC:0184:V014. Both samples of UKMAC6 and UKMAC9 with DF3 sequence T4/16 were isolated from the patient's left corneal scrape. UKMAC9 was identical to $A$. polyphaga ATCC30461, while UKMAC6 was 99\% similar to UKMAC9 where only one nucleotide substitution was found in the outer region of the DF3 sequence. The genotyping results are summarized in Table 1 and Table 3 and

Table 3 Morphological group and cyst diameter for the clinical isolates and percentage of sequence similarity with homologous sequences

\begin{tabular}{llll}
\hline Acanthamoeba isolate & Group & Cyst diameter \pm SEM $(\mu \mathrm{m})$ & BLAST result similarity to homologous sequence $(\%)$ \\
\hline UKMAC1 & III & $15.21 \pm 0.17$ & A. culbertsoni Diamond (100\%) \\
UKMAC2 & \|\| & $15.13 \pm 0.30$ & A. culbertsoni Diamond (100\%) \\
UKMAC3 & \|\| & $15.07 \pm 0.24$ & A. culbertsoni Diamond (100\%) \\
AC20 & \|\| & $13.43 \pm 0.15$ & A. culbertsoni Diamond (100\%) \\
UKMAC5 & $\|$ & $16.54 \pm 0.17$ & A. castellanii CDC:0184:V014 (99\%) \\
UKMAC7 & $\|$ & $16.55 \pm 0.19$ & A. castellanii CDC:0184:V014 (99\%) \\
UKMAC8 & $\|$ & $16.46 \pm 0.09$ & A. castellanii CDC:0184:V014 (99\%) \\
UKMAC9 & $\|$ & $17.20 \pm 0.23$ & A. polyphaga strain ATCC30461 (100\%) \\
UKMAC6 ( 99\% UKMAC9) & $\|$ & $16.73 \pm 0.52$ & A. polyphaga strain ATCC30461 (99\%) \\
UKMAC4 & $\|$ & $16.29 \pm 0.27$ & A. hatchetti strain 2HH (98\%) \\
\hline
\end{tabular}


the phylogenetic tree is shown in Fig. 1. The T4 subgenotyping result is shown in Fig. 2. All sequences generated in this study were submitted to the GenBank database under the accession numbers KY964312-KY964321 (Table 1).

Based on Pussard \& Pons' [8] morphological classification, the result indicated that only four isolates (UKMAC1, UKMAC2, UKMAC3 and AC20) belonged to Group III with the cyst size $<18 \mu \mathrm{m}$ and a smooth endocyst. The range of cyst diameters are represented in Table 3. Another six isolates belonged to Group II, where the cyst sizes were $<18 \mu \mathrm{m}$ and a polygonal endocyst with 6-7 arms (Fig. 3 and Table 3). Xenic samples were able to excyst and proliferate robustly at $37{ }^{\circ} \mathrm{C}$. Only five isolates (AC20, UKMAC2, UKMAC4, UKMAC7 and UKMAC8) were able to be axenized and grown well in the liquid medium at human body temperature $\left(37^{\circ} \mathrm{C}\right)$.

\section{Cytopathic effect}

Cytopathic effect of 5 axenic isolates was carried out for three time intervals (3, 6 and $24 \mathrm{~h}$ ) with three different densities of trophozoite $\left(10^{4}, 10^{5}\right.$ and $10^{6}$ trophozoites/well) on corneal fibroblasts as shown in Fig. 4. There was no cytopathic effect been observed after $24 \mathrm{~h}$ co-incubation with

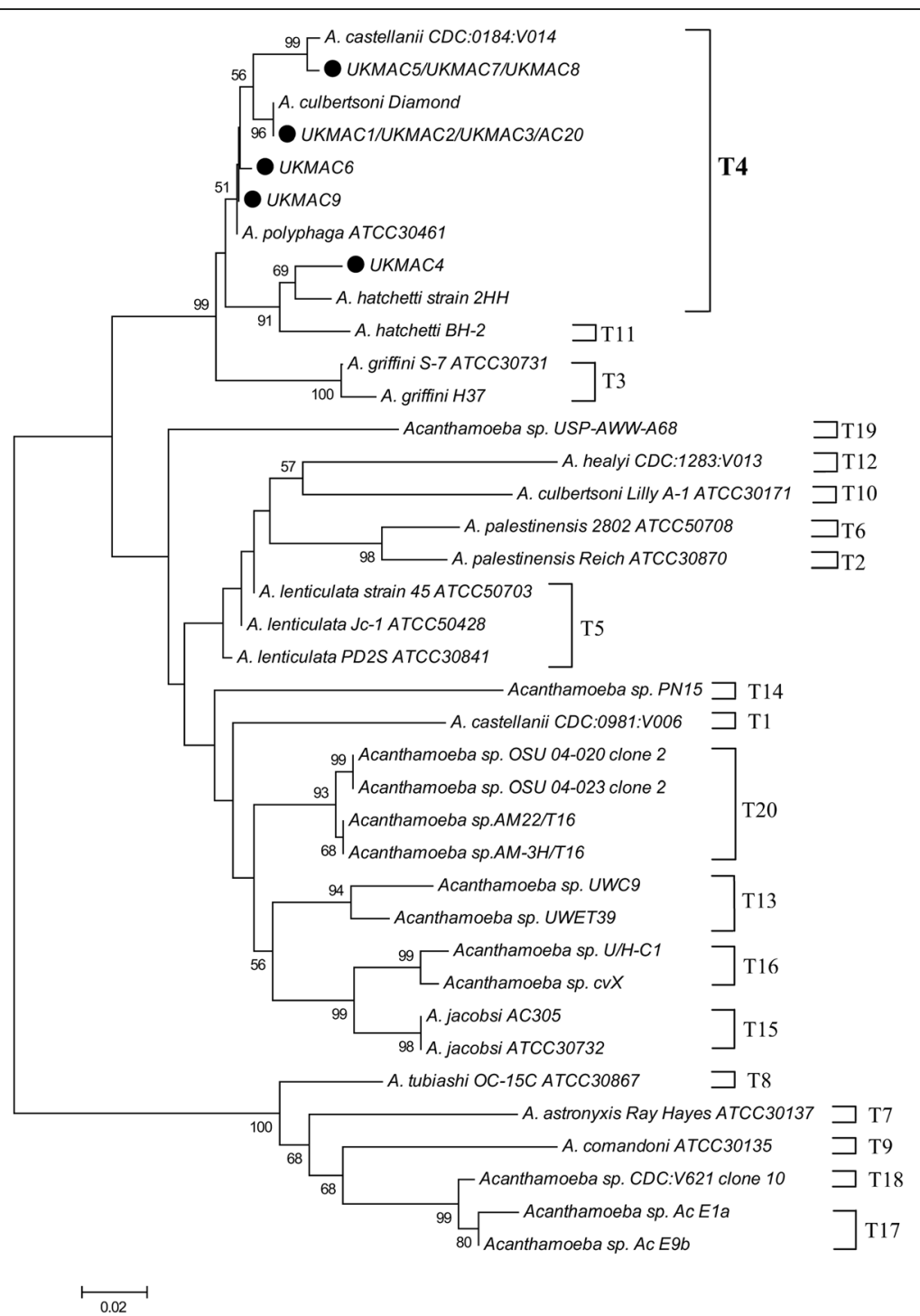

Fig. 1 Evolutionary relationships of taxa. The evolutionary history was inferred using the neighbor-joining method for the 18S rDNA partial sequences of clinical isolates (black dots). The optimal tree with the sum of branch length $=1.25072993$ is shown. The percentage of replicate trees in which the associated taxa clustered together in the bootstrap test (1000 replicates) is shown next to the branches. The tree is drawn to scale, with branch lengths in the same units as those of the evolutionary distances used to infer the phylogenetic tree. The evolutionary distances were computed using the Kimura 2-parameter method and are in the units of the number of base substitutions per site. The analysis involved 38 nucleotide sequences. There were a total of 309 positions in the final dataset. Evolutionary analyses were conducted with MEGA7 


\begin{tabular}{|c|c|c|}
\hline Strains & DF3 Variable Region & T4 \\
\hline & $\begin{array}{lll}* * * * * * & * * * * * * * \\
\end{array}$ & \\
\hline P1CS & GGT-GCGGTCGTCCTTGGCGTC---TCGGTCCTTCACGG--GGCCGGGGCGCGGGGGCGGCTTAGCCCGG & $\mathrm{T} 4 / 1$ \\
\hline P91CS & GGT-GCGGTCATCCTTGGCG-----TTGGTCTTC--AAA--AGCCAGCG--CGGGGGTGGCTTAGCCCGG & $\mathrm{T} 4 / 2$ \\
\hline & GGT-GCGGTCATCCTTGGCG-----TTGGTCTTC--AAA--AGCCAGCG--CGGGGGTGGCTTAGCCCGG & $T 4 / 2$ \\
\hline UKMAC7 & GGT-GCGGTCATCCTTGGCG-----TTGGTCTTC--AAA--AGCCAGCG--CGGGGGTGGCTTAGCCCGG & $T 4 / 2$ \\
\hline UKMAC8 & GGT-GCGGTCATCCTTGGCG-----TTGGTCTTC--AAA--AGCCAGCG--CGGGGGTGGCTTAGCCCGG & \\
\hline & GT-GCGGTCGTCCTTGGCG-G---TTGGTCTTC--AAA--AGCCAGCG-GCGGGGGCGGCTTAGCCCGG & \\
\hline & GGT-GCGGCTGTTCTTGGCGTC-----GGTTTC--------GGCCG--GCGCGGGGATGGCTTAGCCCGG & $\mathrm{T} 4 / 4$ \\
\hline & GT-GCGGTCGTCCTTGGCG-G---TTGGTCTTC--GAA--AGCCAGCG-GCGGGGGCGGCTTAGCCCGG & \\
\hline & ITTGCGGTCGTCCTTGGCGTC---TCGGTTTC---------GGCCGGGGCGCGGGGATGGCTTAGCCCGG & \\
\hline & GGTTGCGGTCGTCCTTGGCGTC---TCGGTTTC--------GGCCGGGGCGCGGGGATGGCTTAGCCCGG & T4/6 \\
\hline & TTGCGGTCGTCCTTGGCGTC---TCGGTTTC---------GGCCGGGGCGCGGGGATGGCTTAGCCCGG & T4/6 \\
\hline & GTTGCGGTCGTCCTTGGCGTC----TCGGTTTC---------GGCCGGGGCGCGGGGATGGCTTAGCCCGG & $\mathrm{T} 4 / 6$ \\
\hline & TTTGCGGTCGTCCTTGGCGTC---TCGGTTTC--------GGCCGGGGCGCGGGGATGGCTTAGCCCGG & $T 4 / 6$ \\
\hline & T-GCGGTCGTCCTTGGCG-----TCGGTTTCG-------GCCGGCG--CGGGGGTGGCTTAGCCCGG & $\mathrm{T} 4 / 7$ \\
\hline & IT-GCGGTCGTCCTTGGCGTC---TCGGTCCTTCACGG--GGCCGGGGCGCGGGGGTGGCTTAGCCCGG & $\mathrm{T} 4 / 8$ \\
\hline & T-GCGGTCGTCCTTGGCGTC---TCGGTTTC--------GGCCGGGGTGCGGGGACGGCTTAGCCCGG & $\mathrm{T} 4 / 9$ \\
\hline & TTGCGGTCGTCCTTGGCGTC---TCGGTTTC--------GGCCGGGGCGCGGGGACGGTTTAGCCCGG & $\mathrm{T} 4 / 10$ \\
\hline & :GC-GCGGTCGTCCTTGGCCGGGTTCTCGTCCTTCACGGGGCGCGGTTCGGCGGGGGCGGCTTAGCCCGA & \\
\hline & GGC-GCGGTCGTCCTTGGCGTG--TCTCGGC-TTCACGG--CTGGGGCGCGCGAGGGCGGTTTAGCCCGG & \\
\hline & ¿C-GCGGTCGTCCTTGGCGTC---TCGGTCCTTCACGG--GGCCGGGGCGCGGGGGCGGCTTA & $\mathrm{T} 4 / 13$ \\
\hline & TTTGCGGTCATCCTTGGCGTC---TCGGTTTC--------GGCCGGGGCGCGGGGATGGCTTAGCCCGG & \\
\hline & GGTTGCGGTCGTCCTTGGCGTC---TCGGTTTC--------GGCCGGGGCGCGGGGACGGTTTACCCCGG & \\
\hline & iT-GCGGTCGTCCTTGGCG-----TCGGTTTCG--------GCCGGCG--CGGGGGCGGCTTAGCCCGG & $\mathrm{T} 4 / 16$ \\
\hline & GTCCTTGGCG-----TCGGTTTCG--------GCCGGCG--CGGGGGCGGCTTAGCCCGG & T4/16 \\
\hline & GGT-GCGGTCGTCCTTGGCG-----TCGGTTTCG--------GCCGGCG--CGGGGGCGGCTTAGCCCGG & \\
\hline & GTCGTCCTTGGCG-G---TTGGTCTTC--AAA--AGC & \\
\hline & CG-T----CGGTCTTC--AAA--AGCCGGC--GCGGGGGTGGCTTAGCCCGG & $\mathrm{T} 4 / 18$ \\
\hline & ATCCTTGGCG-T---TCGGTCTTGCAAAA--GGCCGGCC-GCGGGGGTGGCTTAGCCCGG & \\
\hline & G-----TTGGTCTTC--AAA--AGCCAGCG--CC & \\
\hline & GT-GCGGTCGTCCTTGGCGCG----TTGGTCTTC--AAA--AGCCAGCGCGCGGGGGCGGCTTAGCCCGG & $\mathrm{T} 4 / 21$ \\
\hline & GGT-GCGGTCGTTCTTGGCGTC-----GGTTTC--------GGCCG--GCGCGGGAGCGGCTTAGCCCGG & \\
\hline & T-GCGGTCGTCCTTGGCGTC---TCGGTCCTTCACGG--GGCCGGGGCGCGGGGGTGGCTTAGGCCGG & $\mathrm{T} 4 / 23$ \\
\hline & C-GCGGTCGTCCTTGGCGCG---TTCGTG-TTCACG---CACGGGCGCGCGAGGGCGGCTTAGCCCGG & $\mathrm{T} 4 / 24$ \\
\hline & C-GCGGTCGTCCTTGGCG------TTCGTG-TTCACG----CACGAGCGCG--AGGGCGGTTTAC & \\
\hline & CG-----TCTGTCTTTC--TG--GGCCGGCC--CGGGGGCGGCTTAC & \\
\hline & T-GCGGTCGTCCTTGGCGTC---TCGGTCCTTCACGG--GGCCGGGGCGCGGGGGTGGCTTATGCCGG & $\mathrm{T} 4 / 27$ \\
\hline & C-GCGGTCGTCCTTGGCG------TCGGTCTTTC--TG--GGCCGGCC--CGGGGGCGGCTTAGCCCGG & \\
\hline & T-GCGGTCGTCCTTGGCG-----TCGGTCTTTC--GG--GGCCGGCG--CGGGGACGGCTTAGCCCGG & $\mathrm{T} 4 / 29$ \\
\hline & C-GCGGTCGTCCTTGGCGTC---TCGGTTTC---------GGCCGGGGCGCGGGGACGGCTTAGCCCGG & \\
\hline & GTCGTCCTTGGCG-----TCGGTCTTTC--GG--GGCCGGCG--CGGGGGCGGCTTAGCCCGG & \\
\hline & C-GCGGTCGTCCTTGGCGTCG------GTCCTTCACGGGGC-----CGCCGCGAGGGCGGCTTAGCCCGG & $\mathrm{T} 4 / 32$ \\
\hline & & \\
\hline & TCGTCCTTGGCG----TGTCAGC-TTCACGG--CTGGCG--CGCGAGGGCGGTTTA & \\
\hline & C-GCGGTCGTCCTTGGCGT---TGTCGGC-TTCACGG--CTGGCGG-CGCGAGGGCGGTAGAGCCCGG & $\mathrm{T} 4 / 35$ \\
\hline UKMAC4 & GGC-GCGGTCGTCCTTGGCGTTT-TGTCAGC-TTCACGG--CTGGCGGGCGCGAGGGCGGTTTAGCCCGG & T4/36 \\
\hline
\end{tabular}

Fig. 2 T4 subgenotype of clinical isolates. Primary sequence alignment of a subset of the highly variable and informative region of DF3 (stem 29-1, 185 rRNA) of Malaysian clinical isolates from corneal scrapings and the reference sequences of the T4 Rns genotype. Abbreviations for samples and reference sequences are as defined in Table 1. Sequences were aligned by similarity. Asterisks denote similar positions and gaps are represented as dashes. Samples of the present study are indicated in bold

the density of $10^{4}$ trophozoites/well. The cytopathic effect of corneal fibroblasts was observed after 6 h co-incubation with $10^{5}$ trophozoites and $3 \mathrm{~h}$ co-incubation with $10^{6}$ trophozoites. Sample AC20 exhibited the highest CPE percentage in both densities of $10^{5}$ and $10^{6}$ trophozoites/well throughout the three time intervals. The trophozoites accumulated at the edge of corneal fibroblasts and multiple small lesions were formed due to its cytopathic effect (Fig. 5). The empty spaces between the corneal fibroblasts were increased due to the cytolysis. The corneal fibroblasts had fully been lysed (100\%) after $24 \mathrm{~h}$ co-incubation with $10^{6}$ trophozoites. The cells were replaced by trophozoites and a few cysts which were either attached on the well surface or floating in the medium.

\section{Cytopathic effect correlates with MBP and AhLBP gene expression}

Sample AC20 is the most virulent strain in this study due to it having the highest trophozoite growth rate, gene expression of MBP, and cytopathic effect (Fig. 6). In comparison, the growth rate of trophozoites and gene expression of MBP were the lowest for the strain UKMAC4 among 4 axenic isolates. This study showed a positive correlation between growth rate and cytopathic effect, $r_{(15)}=0.889, P<0.0001$. There was a positive relationship between MBP gene expression and cytopathic effect, $r_{(15)}=0.864, P<0.0001$. There was also a strong relationship between AhLBP gene expression and cytopathic effect, $r_{(15)}=0.934, P<0.0001$. Specific primers of 

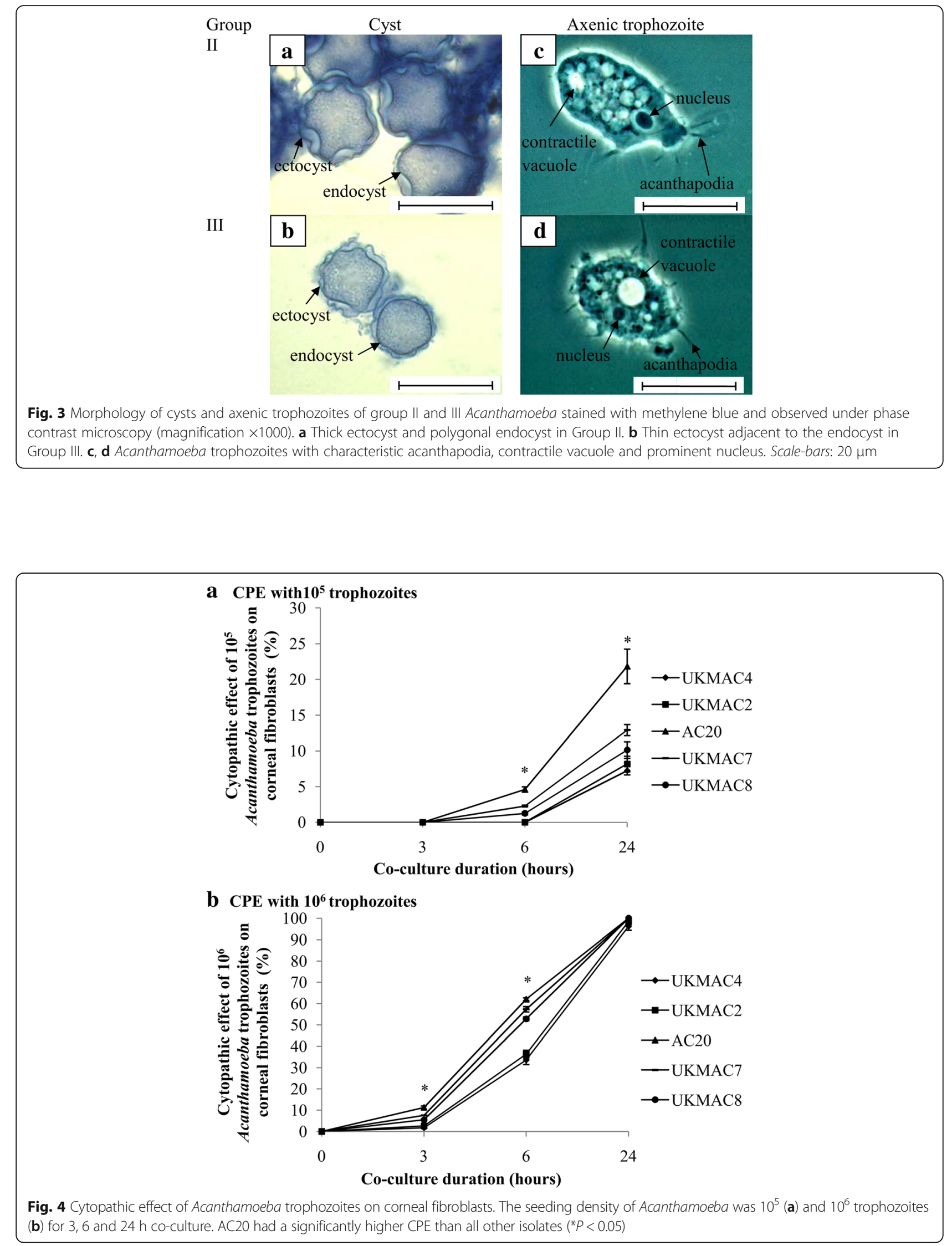


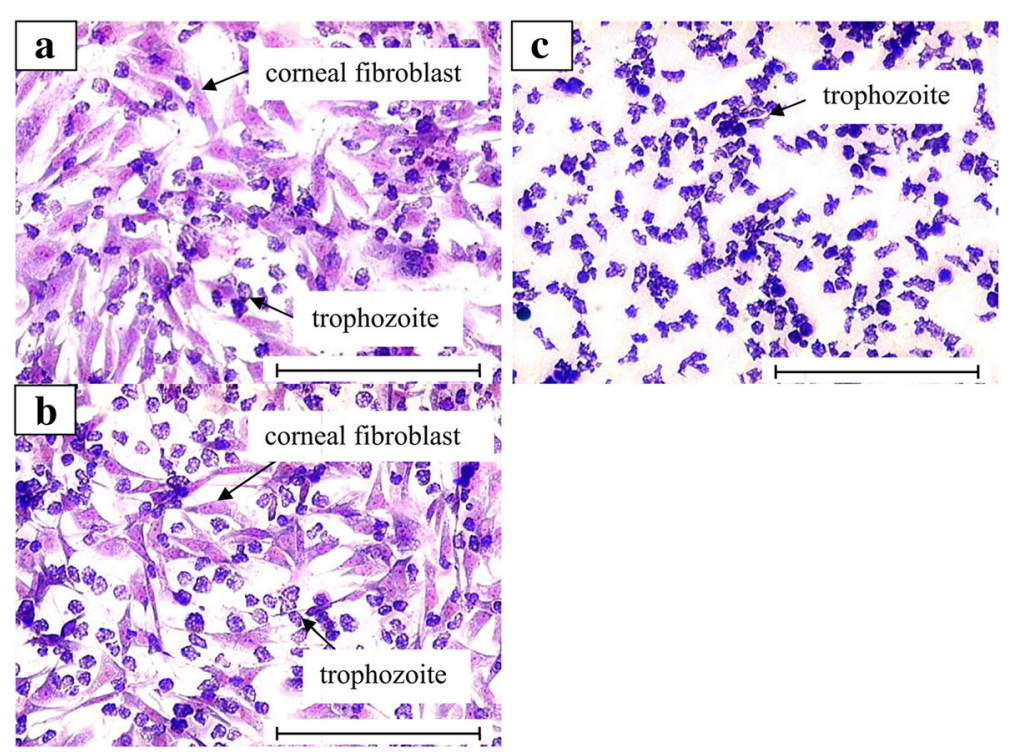

Fig. 5 Cytopathic effect of AC20 isolate on the corneal fibroblasts with seeding of $10^{6}$ trophozoites. a The corneal fibroblasts are fusiform; the Acanthamoeba trophozoites with prominent contractile vacuoles were feeding on the edge of cells and thus forming multiple small lesions on the monolayer cells after $3 \mathrm{~h}$ co-culture. $\mathbf{b}$ The gaps between keratocytes were increased with the time due to the cytopathic effect of trophozoites after $6 \mathrm{~h}$ co-culture. c All corneal fibroblasts were lysed by trophozoites after $24 \mathrm{~h}$ co-culture and only left trophozoites in the vessel. Giemsa staining (magnification $\times 100$ ). Scale-bars: $200 \mu \mathrm{m}$

the studied genes produced a single melt peak in melting curve analysis (Additional file 1: Fig. S1) and a single band of PCR product in 1.5\% agarose gel electrophoresis (Fig. 7). The statistical results of growth rate, virulent gene expression and CPE are shown in Additional file 2: Table S1.

\section{Discussion}

Rns genotypic identification for Acanthamoeba is important in studying the epidemiology of Acanthamoeba keratitis, providing the correlation between genotype and infection [10]. Previous studies found that the T4 genotype is the most predominant causative agent for AK and also morphologically belonging to Group II and III [13]. In this study, all clinical isolates from corneal scrapings were also assigned to genotype $\mathrm{T} 4$, thus providing evidence to support the genotype T4 as a dominant sequence associated with AK in Malaysia. Based on DF3 sequence determination, four isolates (T4/6), three isolates (T4/2), two isolates (T4/16), and one new genotype T4 sequence were identified. The new genotype T4 was suggested as a subgenotype T4/36 in this study. Results revealed that genotype $\mathrm{T} 4 / 2$ and $\mathrm{T} 4 / 6$ were common in keratitis isolates in Malaysia and similar results had been reported from Hong Kong [12], North China [48], France [49] and the USA [10]. Our studied isolates were mainly phylogenetically identical to A. culbertsoni Diamond [14]. From the previous study, 4 out of 11 Acanthamoeba isolates (19.05\%) from air-conditioners in Kuala Lumpur, Malaysia were genotypically identical to $A$. culbertsoni Diamond from keratitis, Ohio, USA [50]. This explained that the distribution of Acanthamoeba with a specific genotype also plays a vital rule in the occurrence of AK. T4 isolates are more prevalent and geographically widespread across the world and this dominant sequence is mostly associated with human infection [14, 24, 51].

A significant issue with the use of contact lenses is that of corneal ulcers, arising from the prolonged wearing of the lens. Contaminated contact lenses or exposure to Acanthamoeba accidentally from the environment could be a risk factor for AK. Acanthamoeba can easily invade the cornea in the event of an ulcer or trauma because mannose glycoprotein would be upregulated in response to the corneal abrasion, and thus increasing the affinity of Acanthamoeba trophozoites in adhering to the corneal epithelium [30]. This reveals that improper contact lens cleaning practices is most likely to be the reason of AK infection [52]. Contact lenses are a good vehicle to transport the Acanthamoeba to the cornea. The biofilm of contact lenses and carbohydrate residues secreted by host could be a good breeding ground and food source for Acanthamoeba to multiply and attach to the contact lens [53]. Moreover, wearing contaminated contact lenses increases the exposure period of Acanthamoeba on the cornea, thus increasing the possibility of AK, especially for those with corneal abrasion or injury.

The density of trophozoites is highly important in causing a cytopathic effect on the monolayer cells in vitro. No cell damage was observed when small inoculums of amoeba were used in the cytopathic effect test $[54,55]$. In this study, $10^{4}$ trophozoites failed to cause a 


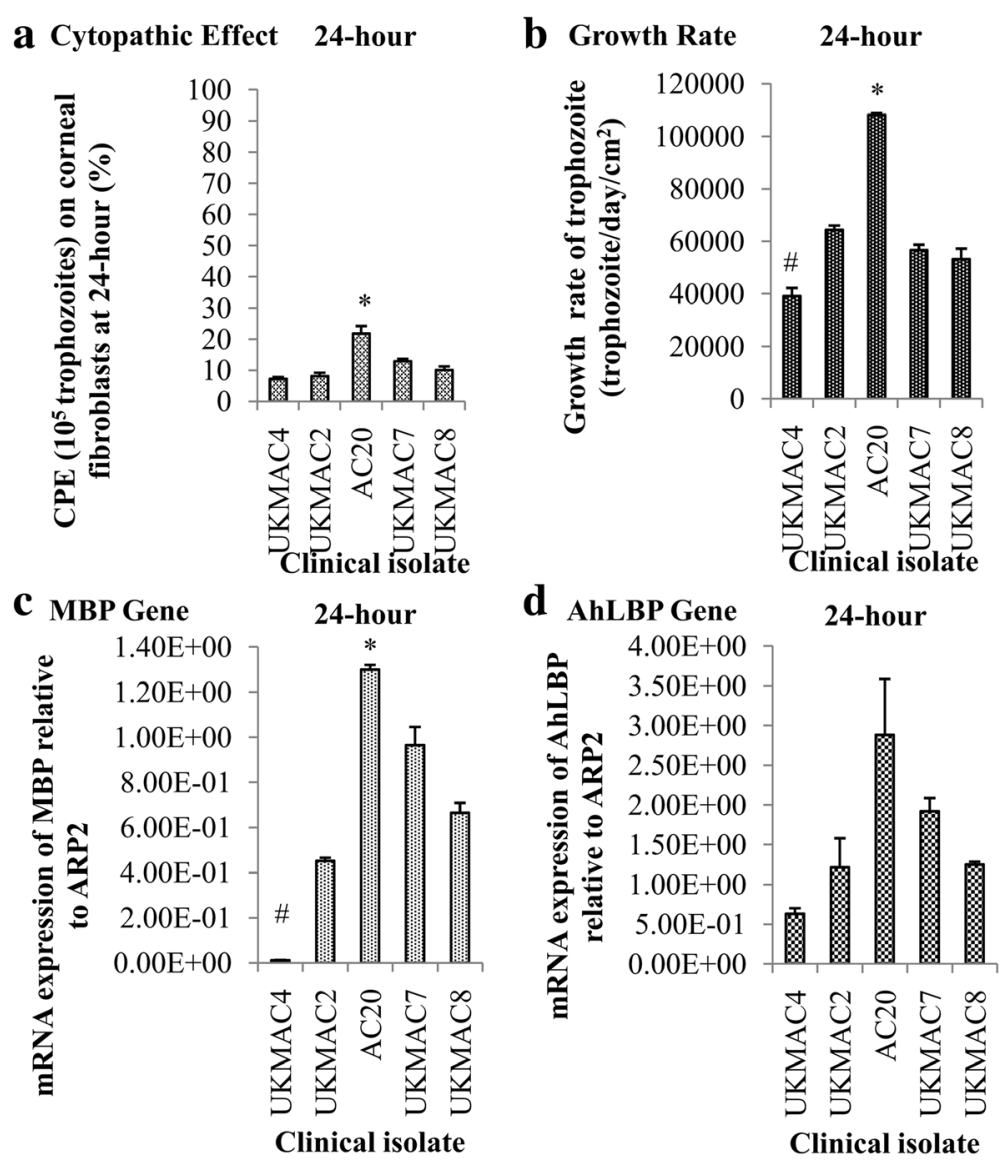

Fig. 6 Cytopathic effect (a), (b) growth rate, mRNA expression of MBP (c) and AhLBP (d) virulent markers of clinical isolates at 24 h. AC20 had a statistically significant higher $C P E$, growth rate and MBP expression as compared to the other isolates ( $(P<0.05)$. UKMAC4 had a statistically significant lower growth rate and MBP expression as compared to the other isolates $(\# P<0.05)$

cytopathic effect even when the incubation time was prolonged to 1 week. The cut off point for corneal fibroblasts is the seeding density of $10^{5}$ trophozoites needed to demonstrate the cytolysis. This revealed that other than the susceptibility of Acanthamoeba to binding with corneal receptors, the ability to multiply and adapt in the cornea is also important in the development of AK. The sequential events of CPE were demonstrated as similar to the previous studies $[55,56]$. Cell shrinkage and gaps were observed at the initial phase of CPE, then some cells were rounded and either engulfed by trophozoites or floating off. The trophozoite-mediated cytopathic effect is due to three independent mechanisms: direct cytolysis, phagocytosis and apoptosis [57]. The clinical strain of Acanthamoeba induced a cytopathic effect on human corneal fibroblasts mainly via apoptosis after direct adhesion rather than through soluble factors [58]. The cytopathic effect was in a dose-dependent manner after co-culture with Acanthamoeba, T4 Acanthamoeba isolates from AK patients and exhibited a similar cytopathic effect on human corneal fibroblasts [58].
In this study, the pathogenic potential of parasites in vitro is directly correlated with the expression level of the MBP. Pathogenic strains of Acanthamoeba, which produce robust amounts of MBP, bind to host cells and produce amoeba-induced cytopathic effects in a mannosedependent manner. In contrast, non-pathogenic strains, which produce little or no MBP, are unable to bind onto the host cells or produce CPE $[27,28]$. The ability of parasites to bind to host cells and produce CPE is directly correlated with the expression of the MBP. Acanthamoeba strains that expressed high level of MBP could bind strongly to host cells and produce potent CPE. The production of MBP was detected by affinity chromatography and western blot analyses [33]. The level of AhLBP mRNA expression was compared between the pathogenic and non-pathogenic Acanthamoeba [31]. Highly virulent strains expressed a higher level of AhLBP mRNA through northern blot analysis. The pathogenic strain has a higher affinity to attach on the extracellular matrix glycoprotein laminin when compared to the non-pathogenic strain in order to induce CPE [26]. 


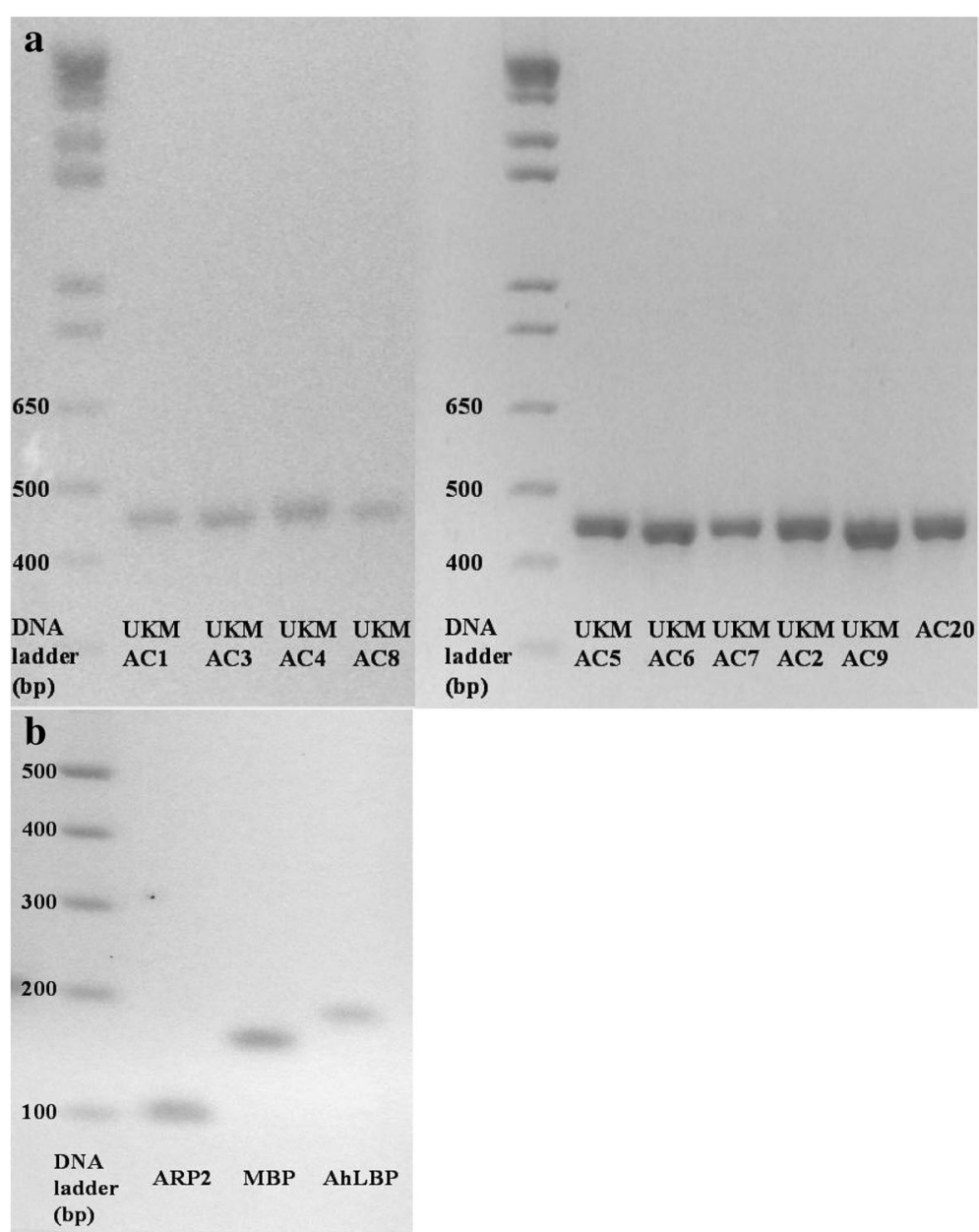

Fig. 7 Agrose gel electrophoresis of PCR products. The products were for the target gene ASA.1 for ten Acanthamoeba isolates (a) and the housekeeping gene ARP2, Acanthamoeba virulent markers MBP and AhLBP genes (b). A single band of PCR product indicated the specificity of the synthesised primers

Previous studies proved that the mannose-binding proteins and laminin-binding proteins on Acanthamoeba are the virulence proteins responsible for the pathogenesis of Acanthamoeba infection [26, 31, 35, 59]. Pre-treated amoeba with the mannose showed a significant decrease in their adhesion and invasion on the collagen matrix and reduced their cytopathic effect [32, 36]. Incubation amoeba with mannose sugars inhibited their attachment on inert surfaces in a dose-dependent way $[59,60]$. Acanthamoeba trophozoites pretreated with anti-MBP IgY antibody significantly inhibited the CPE. Pathogenic A. culbertsoni exhibited high attachment on laminin and cytopathic effect on normal human keratocytes regardless of incubation with or without laminin [26].

This study showed strong a correlation between virulent genes and growth rate. Virulent strains have a higher growth rate and as well as higher virulent gene expression. Physiological characteristics correspond to their degree of virulence. It is also plausible that more trophozoites will cause more cytopathic effect. Pathogenic potential usually correlates to a high growth rate of amoeba [61], although the rapid growth of amoeba on the cells was not necessarily comparable to their growth rate on the axenic culture [62]. Cytopathic potential per trophozoite is more important in affecting the degree of cytopathic effect when compared to their numbers [63].

Although samples UKMAC2 and AC20 have the same DF3, they have a different cytopathic effect, growth rate and expression level of virulent genes. DF3 was used to differentiate their genotype but did not reveal the same phenotype in this study. The difference of phenotypes could be a consequence of developmental variation [64]. Moreover, a complete sequence may be needed to study a relation between the sequence type and phenotypes. Previous studies showed that the sequences belonging to the same DF3 could be with a different V4 region [46]. The V5 variable region includes the highly variable DF3 region and the $\mathrm{V} 4$ region located within the genotypic 
extended fragment were examined to differentiate the Acanthamoeba genotypes [46, 65].

\section{Conclusions}

This study is the first report of $18 \mathrm{~S}$ rDNA identification for clinical isolates in Malaysia. All pathogenic strains belonged to genotype $\mathrm{T} 4$ and one new subgenotype T4/36 (UKMAC4) was identified. This study also showed the first correlation between mRNA expression of Acanthamoeba virulent markers MBP and AhLBP with cytopathic effect. The expression of virulent markers is directly correlated with the cytopathic effect. The detection of mRNA expression of genes MBP and AhLBP can be used to determine the pathogenicity of Acanthamoeba and to study the pathogenesis of Acanthamoeba keratitis.

\section{Additional files}

Additional file 1: Figure S1. Melt curve and melt peak of genes ARP2, MBP and AhLBP in qRT-PCR. a The melting points of genes ARP2, MBP and AhLBP were $86.5^{\circ} \mathrm{C}, 86.5^{\circ} \mathrm{C}$ and $87.5^{\circ} \mathrm{C}$, respectively. b Specific primers of the studied genes produced a single melt peak for each PCR product. (TIFF $6503 \mathrm{~kb}$ )

Additional file 2: Table S1. Statistically significant results of cytopathic effect, trophozoite growth rate and virulent gene expression. The Student's t-test was performed for normally distributed data, while the Mann-Whitney U- test was used as non-parametric test. (DOCX $15 \mathrm{~kb}$ )

\section{Abbreviations}

AhLBP: Acanthamoeba laminin binding protein; AK: Acanthamoeba keratitis; ARP2: Acanthamoeba actin related protein 2; ASA.S1: Acanthamoeba genusspecific amplicon; CDNA: complementary DNA; CPE: cytopathic effect; Ct: threshold cycle; DF3: diagnostic fragment 3; MBP: mannose binding protein; NNA: non-nutrient agar; PAS: PAGE amoebic saline; PYG: peptone, yeast extract, glucose; Rns: 18 S rRNA; SEM: standard error of the mean

\section{Acknowledgements}

We are grateful to Acanthamoeba Culture Laboratory of Parasitology Department, UKM for providing the clinical isolates of Acanthamoeba. We also thank the grant of UKM-GUP-TKP-08-19-068 for sponsoring the cloning kits.

\section{Funding}

This project was funded by UKM Fundamental Grant (Grant No. FF-274-2010).

\section{Availability of data and materials}

The datasets supporting the conclusions of this article are included within the article. The partial $18 \mathrm{~S}$ rRNA sequence of Acanthamoeba isolates are available in the GenBank database under the accession numbers KY964312-KY964321.

\section{Authors' contributions}

Performed the laboratory tests, data analysis and manuscript writing: SN. Directed and managed the project: KC. Guided the genotypic identification of Acanthamoeba: AN. Guided the corneal cell culture: NAG. Provided Acanthamoeba isolates: AN, YS and NAR. All authors read and approved the final manuscript.

\section{Ethics approval}

This project was approved by the Ethics and Research Committee of Universit Kebangsaan Malaysia Medical Centre, reference number FF-274-2010. The use of rabbit corneal cells was approved by UKM Animal Ethics Committee with reference number FP/FISIO/2012/CHUA/18-JANURAY/420-JANUARY-2012-JUNE2013-AR-CAT2.

\section{Consent for publication}

Not applicable.

\section{Competing interests}

The authors declare that they have no competing interests.

\section{Publisher's Note}

Springer Nature remains neutral with regard to jurisdictional claims in published maps and institutional affiliations.

\section{Author details}

'Department of Physiology, Faculty of Medicine, Universiti Kebangsaan Malaysia, Jalan Yaacob Latif, 56000 Kuala Lumpur, Bandar Tun Razak, Malaysia. ${ }^{2}$ Department of Parasitology and Medical Entomology, Faculty of Medicine, Universiti Kebangsaan Malaysia, Jalan Yaacob Latif, 56000 Kuala Lumpur, Bandar Tun Razak, Malaysia. ${ }^{3}$ Department of Anatomy, Faculty of Medicine, Universiti Kebangsaan Malaysia, Jalan Yaacob Latif, 56000 Kuala Lumpur, Bandar Tun Razak, Malaysia.

Received: 7 June 2017 Accepted: 21 November 2017

Published online: 28 December 2017

References

1. Lorenzo-Morales J, Khan NA, Walochnik J. An update on Acanthamoeba keratitis: diagnosis, pathogenesis and treatment. Parasite. 2015;22:10.

2. Anisah N, Yusof S, Rahimah I, Norhayati M. Isolation of Acanthamoeba spp. from domestic water tap. Trop Biomed. 2003;20(1):87-9.

3. Khan NA. Pathogenesis of Acanthamoeba infections. Microb Pathog. 2003:34(6):277-85.

4. Illingworth CD, Cook SD. Acanthamoeba keratitis. Surv Ophthalmol. 1998; 42(6):493-508.

5. Seal D. Acanthamoeba keratitis update - incidence, molecular epidemiology and new drugs for treatment. Eye. 2003;17(8):893-905.

6. Lindsay RG, Watters G, Johnson R, Ormonde SE, Snibson GR. Acanthamoeba keratitis and contact lens wear. Clin Exp Optom. 2007;90(5):351-60.

7. Kamel AM, Norazah A. First case of Acanthamoeba keratitis in Malaysia. Trans R Soc Trop Med Hyg. 1995;89(6):652

8. Pussard M, Pons R. Morphology of cystic wall and taxonomy of genus Acanthamoeba (protozoa, Amoebida). Protistologica. 1977;13(4):557-98.

9. Sawyer TK. Acanthamoeba griffini, a new species of marine amoeba. J Protozool. 1971;18(4):650-4.

10. Ledee D, lovieno A, Miller D, Mandal N, Diaz M, Fell J, et al. Molecular identification of T4 and T5 genotypes in isolates from Acanthamoeba keratitis patients. J Clin Microbiol. 2009;47(5):1458-62.

11. Schroeder JM, Booton GC, Hay J, Niszl IA, Seal DV, Markus MB, et al. Use of subgenic 185 ribosomal DNA PCR and sequencing for genus and genotype identification of Acanthamoebae from humans with keratitis and from sewage sludge. J Clin Microbiol. 2001;39(5):1903-11.

12. Booton G, Kelly D, Chu Y-W, Seal D, Houang E, Lam D, et al. $18 \mathrm{~S}$ ribosomal DNA typing and tracking of Acanthamoeba species isolates from corneal scrape specimens, contact lenses, lens cases, and home water supplies of Acanthamoeba keratitis patients in Hong Kong. J Clin Microbiol. 2002:40(5):1621-5.

13. Gast RJ, Ledee DR, Fuerst PA, Byers TJ. Subgenus systematics of Acanthamoeba: four nuclear $18 \mathrm{~S}$ rDNA sequence types. J Eukaryot Microbiol. 1996;43(6):498-504.

14. Stothard DR, Schroeder-Diedrich JM, Awwad MH, Gast RJ, Ledee DR, Rodriguez-Zaragoza S, et al. The evolutionary history of the genus Acanthamoeba and the identification of eight new 185 rRNA gene sequence types. J Eukaryot Microbiol. 1998;45(1):45-54

15. Horn M, Fritsche TR, Gautom RK, Schleifer KH, Wagner M. Novel bacterial endosymbionts of Acanthamoeba spp. related to the Paramecium caudatum symbiont Caedibacter caryophilus. Environ Microbiol. 1999;1(4):357-67.

16. Gast RJ. Development of an Acanthamoeba-specific reverse dot-blot and the discovery of a new ribotype. J Eukaryot Microbiol. 2001;48(6):609-15.

17. Hewett MK, Robinson BS, Monis PT, Saint CP. Identification of a new Acanthamoeba $18 \mathrm{~S} r R N A$ gene sequence type, corresponding to the species Acanthamoeba jacobsi sawyer, Nerad and Visvesvara, 1992 (Lobosea: Acanthamoebidae). Acta Protozool. 2003;42(4):325-30.

18. Corsaro D, Venditti D. Phylogenetic evidence for a new genotype of Acanthamoeba (Amoebozoa, Acanthamoebida). Parasitol Res. 2010;107(1):233-8.

19. Nuprasert W, Putaporntip C, Pariyakanok L, Jongwutiwes S. Identification of a novel T17 genotype of Acanthamoeba from environmental isolates and T10 genotype causing keratitis in Thailand. J Clin Microbiol. 2010;48(12):4636-40. 
20. Qvarnstrom Y, Nerad TA, Visvesvara GS. Characterization of a new pathogenic Acanthamoeba species, A. byersi n. sp., isolated from a human with fatal amoebic encephalitis. J Eukaryot Microbiol. 2013;60(6):626-33.

21. Corsaro D, Walochnik J, Köhsler M, Rott MB. Acanthamoeba misidentification and multiple labels: redefining genotypes T16, T19, and T20 and proposal for Acanthamoeba micheli sp. nov. (genotype T19). Parasitol Res. 2015;114(7):2481-90.

22. Maghsood AH, Sissons J, Rezaian M, Nolder D, Warhurst D, Khan NA. Acanthamoeba genotype T4 from the UK and Iran and isolation of the T2 genotype from clinical isolates. J Med Microbiol. 2005;54(8):755-9.

23. Walochnik J, Haller-Schober E-M, Kölli H, Picher O, Obwaller A, Aspöck H. Discrimination between clinically relevant and nonrelevant Acanthamoeba strains isolated from contact lens-wearing keratitis patients in Austria. J Clin Microbiol. 2000;38(11):3932-6.

24. Di Cave D, Monno R, Bottalico P, Guerriero S, D'amelio S, D'orazi C, et al. Acanthamoeba T4 and T15 genotypes associated with keratitis infections in Italy. Eur J Clin Microbiol Infect Dis. 2009;28(6):607-12.

25. Khan NA, Jarroll EL, Panjwani N, Cao Z, Paget TA. Proteases as markers for differentiation of pathogenic and nonpathogenic species of Acanthamoeba. J Clin Microbiol. 2000;38(8):2858-61.

26. Rocha-Azevedo BD, Jamerson M, Cabral GA, Silva-Filho FC, Marciano-Cabral F. Acanthamoeba interaction with extracellular matrix glycoproteins: biological and biochemical characterization and role in cytotoxicity and invasiveness. J Eukaryot Microbiol. 2009;56(3):270-8.

27. Garate M, Cubillos I, Marchant J, Panjwani N. Biochemical characterization and functional studies of Acanthamoeba mannose-binding protein. Infect Immun. 2005;73(9):5775-81.

28. Panjwani N. Pathogenesis of Acanthamoeba keratitis. Ocul Surf. 2010;8(2):70-9.

29. Alizadeh $\mathrm{H}_{1} \mathrm{Li} \mathrm{H}$, Neelam S, Niederkorn JY. Modulation of corneal and stromal matrix metalloproteinase by the mannose-induced Acanthamoeba cytolytic protein. Exp Eye Res. 2008;87(3):286-91.

30. Clarke DW, Niederkorn JY. The pathophysiology of Acanthamoeba keratitis. Trends Parasitol. 2006:22(4):175-80.

31. Hong $\mathrm{Y}-\mathrm{C}$, Lee W-M, Kong $\mathrm{H}-\mathrm{H}$, Jeong $\mathrm{H}-J$, Chung D-I. Molecular cloning and characterization of a CDNA encoding a laminin-binding protein (AhLBP) from Acanthamoeba healyi. Exp Parasitol. 2004;106(3):95-102.

32. Rocha-Azevedo BD, Jamerson M, Cabral GA, Marciano-Cabral F. Acanthamoeba culbertsoni: analysis of amoebic adhesion and invasion on extracellular matrix components collagen I and laminin-1. Exp Parasitol. 2010;126(1):79-84

33. Garate M, Marchant J, Cubillos I, Cao Z, Khan NA, Panjwani N. In vitro pathogenicity of Acanthamoeba is associated with the expression of the mannose-binding protein. Invest Ophthalmol Vis Sci. 2006;47(3):1056-62

34. Niyyati M, Rezaie S, Babaei Z, Rezaeian M. Molecular identification and sequencing of mannose binding protein (MBP) gene of Acanthamoeba palestinensis. Iran J Parasitol. 2010;5(1):1.

35. Garate M, Cao Z, Bateman E, Panjwani N. Cloning and characterization of a novel mannose-binding protein of Acanthamoeba. J Biol Chem. 2004; 279(28):29849-56.

36. Kim J-H, Matin A, Shin H-J, Park H, Yoo K-T, Yuan X-Z, et al. Functional roles of mannose-binding protein in the adhesion, cytotoxicity and phagocytosis of Acanthamoeba castellanii. Exp Parasitol. 2012;132(2):287-92.

37. Kumar S, Stecher G, Tamura K. MEGA7: Molecular Evolutionary Genetics Analysis version 7.0 for bigger datasets. Mol Biol Evol. 2016:33:1870-4.

38. Saitou N, Nei M. The neighbor-joining method: a new method for reconstructing phylogenetic trees. Mol Biol Evol. 1987;4(4):406-25.

39. Felsenstein J. Confidence limits on phylogenies: an approach using the bootstrap. Evolution. 1985;39:783-91.

40. Kimura M. A simple method for estimating evolutionary rates of base substitutions through comparative studies of nucleotide sequences. J Mol Evol. 1980;16(2):111-20.

41. Ghafar NA, Latif ESE, Woon CK, Luan NS, Hamzah JC, Hui CK. In vitro characterization of corneal cells: a step towards bioengineered cornea; 2015. p. 4.

42. Le Bail A, Dittami SM, de Franco P-O, Rousvoal S, Cock MJ, Tonon T, et al. Normalisation genes for expression analyses in the brown alga model Ectocarpus siliculosus. BMC Mol Biol. 2008;9(1):75.

43. Sáez CA, Ramesh K, Greco M, Bitonti MB, Brown MT. Enzymatic antioxidant defences are transcriptionally regulated in Es524, a copper-tolerant strain of Ectocarpus siliculosus (Ectocarpales, Phaeophyceae). Phycologia. 2015;54(4):425-9.

44. Zhao G, Sun S, Zhao J, Xie L. Genotyping of Acanthamoeba isolates and clinical characteristics of patients with Acanthamoeba keratitis in China. Med Microbiol. 2010;59(4):462-6.
45. Abe N, Kimata I. Genotyping of Acanthamoeba isolates from corneal scrapings and contact lens cases of Acanthamoeba keratitis patients in Osaka, Japan. Jpn J Infect Dis. 2010;63(63):299-301.

46. Risler A, Coupat-Goutaland B, Pélandakis M. Genotyping and phylogenetic analysis of Acanthamoeba isolates associated with keratitis. Parasitol Res. 2013;112(11):3807-16

47. Duarte JL, Furst C, Klisiowicz DR, Klassen G, Costa AO. Morphological, genotypic, and physiological characterization of Acanthamoeba isolates from keratitis patients and the domestic environment in Vitoria, Espírito Santo, Brazil. Exp Parasitol. 2013;135(1):9-14.

48. Zhang $Y$, Sun $X$, Wang Z, Li R, Luo S, Jin X, et al. Identification of $18 \mathrm{~S}$ ribosomal DNA genotype of Acanthamoeba from patients with keratitis in North China. Invest Ophthalmol Vis Sci. 2004;45(6):1904-7.

49. Yera H, Zamfir O, Bourcier T, Viscogliosi E, Noël C, Dupouy-Camet J, et al. The genotypic characterisation of Acanthamoeba isolates from human ocular samples. Br J Ophthalmol. 2008;92(8):1139-41.

50. Chan L-L, Mak J-W, Low Y-T, Koh T-T, Ithoi I, Mohamed SM. Isolation and characterization of Acanthamoeba spp. from air-conditioners in Kuala Lumpur, Malaysia. Acta Trop. 2011;117(1):23-30.

51. Marciano-Cabral F, Cabral G. Acanthamoeba spp. as agents of disease in humans. Clin Microbiol Rev. 2003;16(2):273-307.

52. Rivera WL, Adao DEV. 185 ribosomal DNA genotypes of Acanthamoeba species isolated from contact lens cases in the Philippines. Parasitol Res. 2009;105(4):1119.

53. Simmons PA, Tomlinson A, Seal DV. The role of Pseudomonas aeruginosa biofilm in the attachment of Acanthamoeba to four types of hydrogel contact lens materials. Optom Vis Sci. 1998;75(12):860-6.

54. Larkin D, Berry M, Easty D. In vitro corneal pathogenicity of Acanthamoeba. Eye. 1991;5(Pt 5):560-8.

55. Kinnear FB. Acanthamoeba pathogenicity for corneal cells. J Inf Secur. 2004; 49(4):310-6.

56. Badenoch PR, Adams M, Coster DJ. Corneal virulence, cytopathic effect on human keratocytes and genetic characterization of Acanthamoeba. Int J Parasitol. 1995;25(2):229-39.

57. Lakhundi S, Siddiqui R, Khan NA. Pathogenesis of microbial keratitis. Microb Pathog. 2016;104:97-109

58. Takaoka-Sugihara N, Yamagami S, Yokoo S, Matsubara M, Yagita K Cytopathic effect of Acanthamoeba on human corneal fibroblasts. Mol Vis. 2012;18:2221.

59. Imbert-Bouyer S, Merlaud A, Imbert C, Daniault G, Rodier M-H. A mannose binding protein is involved in the adherence of Acanthamoeba species to inert surfaces. FEMS Microbiol Lett. 2004;238(1):207-11.

60. Yoo K-T, Jung S-Y. Effects of mannose on pathogenesis of Acanthamoeba castellanii. Korean J Parasitol. 2012;50(4):365.

61. Walochnik J, Obwaller A, Aspöck H. Correlations between morphological, molecular biological, and physiological characteristics in clinical and nonclinical isolates of Acanthamoeba spp. Appl Environ Microbiol. 2000; 66(10):4408-13.

62. Pumidonming W, Koehsler M, Walochnik J. Acanthamoeba strains show reduced temperature tolerance after long-term axenic culture. Parasitol Res. 2010;106(3):553-9.

63. Hurt M, Niederkorn J, Alizadeh H. Effects of mannose on Acanthamoeba castellanii proliferation and cytolytic ability to corneal epithelial cells. Invest Ophthalmol Vis Sci. 2003;44(8):3424-31.

64. Vogt $G$, Huber M, Thiemann M, van den Boogaart G, Schmitz OJ, Schubart CD. Production of different phenotypes from the same genotype in the same environment by developmental variation. J Exp Biol. 2008;211(4):510-23.

65. Lee JC, Gutell RR. A comparison of the crystal structures of eukaryotic and bacterial SSU ribosomal RNAs reveals common structural features in the hypervariable regions. PLoS One. 2012;7(5):e38203. 